\title{
A APLICAÇÃO DA RESPONSABILIDADE PELA PERDA DE UMA CHANCE COMO DECORRÊNCIA DO DIREITO FUNDAMENTAL À CONVIVÊNCIA FAMILIAR DE CRIANÇAS E ADOLESCENTES
}

\author{
Claudio José Amaral Bahia ${ }^{1}$ \\ Leticia Nascimbem Colovati ${ }^{2}$
}

Resumo: A possibilidade de aplicação da perda de uma chance como decorrência do direito fundamental à convivência familiar e comunitária das crianças e adolescentes, a partir da aplicação dos princípios da prioridade absoluta e da proteção integral, é o tema do presente estudo, o qual aborda a evolução da família e o especial status a ela conferido, sendo decorrência deste, o direito à convivência familiar e comunitária dos infantes, pautando-se pelos princípios da dignidade humana e da igualdade, de modo a demonstrar a possibilidade de responsabilização do Estados e de seus entes quando da inépcia ou inércia na concretização deste direito.

Palavra-chave: Perda de uma chance. Responsabilidade Estatal. Convivência familiar e comunitária.

\section{THE APPLICATION OF RESPONSABILITY FOR THE LOSS OF A CHANCE AS A CONSEQUENCE OF THE FUNDAMENTAL RIGHT TO THE FAMILY LIVING OF CHILDREN AND ADOLESCENTS}

\begin{abstract}
The possibility of applying the loss of a chance as a result of the fundamental right to family and community coexistence of children and adolescents, based on the application the principles of absolute priority and integral protection, is the theme of this study, which addresses the evolution of the family and the special status conferred upon it, the result of which is the right to family and community life of infants, based on the principles of human dignity and equality, in order to demonstrate the possibility of holding States accountable when ineptitude or inertia in the realization of this right.
\end{abstract}

Keywords: Loss of a chance. State Responsibility. Family and community life.

\section{INTRODUÇÃO}

Indubitável é a afirmação de que o Estado deve proteger a família - base da sociedade -, de modo a resguardar todos os direitos a ela inerentes, em suas diversas fases, devendo zelar, dentro de tal contexto, pelos direitos fundamentais da criança e do adolescente,

\footnotetext{
${ }^{1}$ Doutor em Direito do Estado, sub-área Direito Constitucional, pela Pontifícia Universidade Católica de São Paulo. Professor do Centro Universitário de Bauru e da Faculdade Iteana de Botucatu. Advogado.

${ }^{2}$ Mestranda em Sistema Constitucional de Garantia de Direitos - Centro Universitário de Bauru, mantido pela Instituição Toledo de Ensino - ITE/Bauru, Advogada.
} 
inclusive a partir da efetiva aplicação dos princípios da prioridade absoluta e da proteção integral.

O texto constitucional brasileiro, no caput de seu artigo 226, é inconteste ao proclamar que "a família, base da sociedade, tem especial proteção do Estado".

Para Cristiano Chaves de Farias e Nelson Rosenvald (2014, p.42) “o espaço da família, na ordem jurídica, se justifica como um núcleo privilegiado para o desenvolvimento da pessoa humana".

Com efeito, a Constituição Federal de 1988 assegurou, com caráter de norma fundamental, o direito à convivência familiar e comunitária as crianças e aos adolescentes.

Logo, se o direito fundamental à convivência familiar e comunitária foi expressamente assegurado pelo Texto Político, devem, obviamente, existir mecanismos aptos a defender, concretizar e reparar - em casos de malferimentos - seu respectivo exercício, bem como as políticas públicas a ele complementares.

É necessário que o Estado proporcione à família (e a seus componentes - presentes e futuros), condições dignas de sobrevivência, como educação, trabalho, moradia e saúde, de modo que esta possua plenas condições de desenvolver-se.

Ocorre que, no cenário atual, não são poucos os casos em que o direito fundamental à convivência familiar e comunitária da criança e do adolescente resta violado, violando-se, consequentemente, a dignidade do núcleo familiar.

Também se nota, na prática, a ausência de positivação específica no tocante às hipóteses violadoras do direito fundamental em voga, surgindo, daí, a necessidade em se buscar no ordenamento jurídico, meios passíveis de suprir referida lacuna legislativa, objetivando a responsabilização e a reparação da injusta violação que lhes fora impelida.

Nesse liame, questiona-se: quem detém o dever, a obrigação de concretizar e respeitar esse direito, a fim de perseguir a devida responsabilização?

Ademais, seria possível buscar a responsabilização do Estado pela violação do direito fundamental à convivência familiar e comunitária aplicando a teoria da perda de uma chance?

Desse modo, o presente artigo utilizar-se-á de metodologia bibliográfica e documental, tendo em vista a análise das compilações doutrinárias, das legislações nacionais, bem como de documentos de instituições e órgãos nacionais atinentes ao tema. 
No que tange aos objetivos, adotou-se pesquisa exploratória, pois realizadas pesquisas bibliográficas; e pesquisa descritiva, porque os fatos ligados ao fenômeno do presente estudo foram analisados e interpretados.

Discorrendo-se em um primeiro momento, sobre a evolução da família e o status especial conferido a esta pelo texto da Constituição, para, depois, chegar-se a fundamentalidade do direito à convivência familiar e comunitária da criança e do adolescente.

Abordou-se, ademais, os panoramas gerais da teoria da perda de uma chance, o modus operandi de responsabilização estatal solidária, e a consequente possibilidade de responsabilizar o Estado, e seus entes federados, quando da inércia, ou ainda, inépcia, da concretização do direito fundamental à convivência familiar e comunitária e suas decorrências.

\section{DA FUNDAMENTALIDADE DO DIREITO À CONVIVÊNVIA FAMILIAR E COMUNITÁRIA E A RESPONSABILIZAÇÃO DO ESTADO PELA PERDA DE UMA CHANCE}

A Constituição Federal de 1988 é promulgada com vistas ao garantismo, de modo a dirimir preconceitos e prezar pela igualdade e, principalmente, pela dignidade da pessoa humana prevista no artigo $1^{\circ}$, III da Constituição da República.

Esse novo olhar conferido ao ser humano e o rompimento com determinados ideais arraigados na sociedade, influenciou, sem sombra de dúvidas, o Direito de Família, que precisou desatar-se de ultrapassadas concepções, como a desigualdade entre o homem e a mulher na relação conjugal (no sentido de superioridade masculina), como a ilegitimidade dos filhos (haja vista que o Estado legitimara todas as formas de filiação) e como o casamento tido como a única forma legítima de composição familiar. (PEREIRA, 2012).

Com efeito, a família passou a exercer uma função social dotada de valiosa importância dentro da sociedade, daí decorrendo o princípio da função social da família, através do qual despontam uma série de efeitos, tais como a igualdade entre os cônjuges e conviventes, o respeito às diferenças quando da união homoafetiva e a importância da introdução da criança e do adolescente em suas famílias naturais ou substitutas. (GAGLIANO, PAMPLONA, 2015).

Indiscutivelmente, a Constituição Federal, pelos termos do caput de seu artigo 226 imprimiu especial status à família, conferindo também ao Estado o dever de proteção desta, 
objetivando resguardar e efetivar os direitos a ela inerentes.

E não poderia ser diferente.

Aliás, mister ressaltar que, da proteção conferida à família pelo texto constitucional em seus artigos 226 e 227, decorrem os princípios da prioridade absoluta e da proteção integral da criança e do adolescente, os quais devem, por óbvio, serem resguardados pelo Estado Democrático de Direito.

Para Pablo Stolze Gagliano e Rodolfo Pamplona Filho (2015, p. 100) "educação, saúde, lazer, alimentação, vestuário, enfim, todas as diretrizes constantes na Política Nacional da Infầncia e Juventude devem ser observadas rigorosamente".

Importando sublinhar que, no plano internacional, deve-se conferir destaque à Convenção sobre os Direitos das Crianças, da Organização das Nações Unidas, vigente desde o ano de 1990, sendo o tratado com o maior número de ratificações atualmente. De acordo com Alto Comissariado de Direitos Humanos da ONU, a convenção conta com 196 Estadospartes.

Nas palavras de Flávia Piovesan (2017, p. 498) “a convenção acolhe a concepção do desenvolvimento integral da criança, reconhecendo-a como verdadeiro sujeito de direito, a exigir proteção especial e absoluta prioridade".

Umbilicalmente ligado aos princípios acima mencionados, está o direito fundamental à convivência familiar e comunitária da criança e do adolescente, conferido e resguardado pela Constituição Federal, que, nos termos do caput do artigo 227: “é dever da família, da sociedade e do Estado assegurar à criança, ao adolescente e ao jovem, com absoluta prioridade, o direito à (...) convivência familiar e comunitária”.

Afirma Emília Lopes (2016, p. 148) que:

\begin{abstract}
Previsto pela primeira vez no ordenamento jurídico interno, o direito à convivência familiar e comunitária tem por escopo garantir à criança e ao adolescente uma convivência harmoniosa no seio de sua família e localidade - preferencialmente as de origem - num ambiente de amor, afetividade e compreensão, com vistas a proporcionar-lhes o completo e sadio desenvolvimento da personalidade e, ainda, contribuindo com a superação da "cultura da institucionalização".
\end{abstract}

A consecução do direito fundamental à convivência familiar e comunitária da criança e do adolescente recai sobre o Estado, como bem frisou, expressamente, o texto da Lei maior. E não só o texto da Constituição prevê mencionado dever, como também o texto da Convenção Internacional sobre os Direitos das Crianças; Ao tratar sobre o assunto, afirma 


\section{A APLICAÇÃO DA RESPONSABILIDADE PELA PERDA DE UMA CHANCE COMO DECORRÊNCIA DO DIREITO FUNDAMENTAL À CONVIVÊNCIA FAMILIAR DE CRIANÇAS E ADOLESCENTES}

Flávia Piovesan (2017, p. 499) que "ao ratificarem a Convenção, os Estados-partes se comprometem a proteger a criança de todas as formas de discriminação e assegurar-lhe assistência apropriada".

Corroborando a Lei $n^{\circ} 8.069 / 90$, também nomeada como Estatuto da Criança e do Adolescente, que, em perfeita consonância com o texto da Carta de Outubro, determinou nos termos de seu artigo 70, que "é dever de todos prevenir a ocorrência de ameaça ou violação dos direitos da criança e do adolescente".

Não há como excluir, pois, da interpretação do vocábulo "todos", a responsabilidade do Estado.

Sendo importante ressaltar, assim, que a regra é que pais e filhos (crianças e adolescentes) permaneçam juntos, de modo que o afastamento do lar configura extrema exceção.

Dispondo o artigo 23 e Parágrafo único do Estatuto da Criança e do Adolescente:

Art. 23. A falta ou carência de recursos materiais não constitui motivo suficiente para a perda ou a suspensão do pátrio poder.

$[\ldots]$

Parágrafo único. Não existindo outro motivo que por si só autorize a decretação da medida, a criança ou o adolescente será mantido em sua família de origem, a qual deverá obrigatoriamente ser incluída em programas de auxílio.

É necessário, entretanto, que sejam proporcionados à família, condições dignas de subsistência, como saúde, educação, saneamento básico, trabalho, moradia, para que assim, pais e filhos tenham condições dignas de pleno desenvolvimento dentro do seio familiar, principalmente a criança e o adolescente.

Sendo dever do Estado proporcionar o tanto mencionado acima.

Vale dizer, a partir do momento em que o poder estatal concede condições dignas e adequadas de educação, trabalho e saúde, por exemplo, também estará possibilitando o fortalecimento do seio familiar e evitando o sério afastamento do infante de seu lar.

É preciso fazer valer o direito das crianças e adolescentes de crescerem, se desenvolverem e serem educados dentro do âmbito familiar, bem como da comunidade que os cerca, priorizando sempre, primeiramente, a recuperação do ambiente familiar, substituindo, sempre que possível, a extremada retirada do infante de sua família, por ações e políticas públicas inclinadas ao apoio desta, ou ainda, optar por alternativas como as famílias acolhedoras (art. 34, Lei 8.069/90). 
Dessa forma, se levadas a efeito as políticas públicas condizentes, concretizando os princípios da prioridade absoluta e da proteção integral de crianças e adolescentes, certamente o Estado estará tornando real, concreto, o direito constitucional fundamental à convivência familiar e comunitária.

Aliás, a violação do direito fundamental de convivência familiar e comunitária, como consequência inegável da injusta desigualdade que provoca, também afeta, sem sombra de dúvidas, o exercício da cidadania por aqueles que acabaram sendo prejudicados pela ineficiência estatal.

A pessoa que necessita se preocupar com a ausência da sua família, de comida, de saúde e higiene, de educação básica, de água encanada, de carinho, solidariedade e afeto, não detém condições mínimas de se ambientar e de se preocupar com os rumos ou com os destinos de seu País. Não mesmo.

Como explicar a quem não tem o que comer o que significa o sistema proporcional regente da eleição dos parlamentares no Brasil e pedir que seu voto seja livre e consciente? Um tanto quanto paradoxal.

Por extenso período o conceito de cidadania esteve, de certa forma, preso ao exercício pleno dos direitos políticos, isto é, a legitimidade de participação no processo eleitoral.

Em contrapartida, atualmente o que se nota é um alargamento desse conceito, no empenho de que também se verifique sua participação na vida da comunidade, nas discussões e diretrizes governamentais, e, sobretudo, na concretização das proteções e garantias fundamentais do ser humano (BAHIA, 2007).

Nesse passo, cabe enfatizar a lição de Paulo Ferreira da Cunha (2007, p. 61):

\begin{abstract}
Os desafios que se nos colocam à Cidadania já não podem ser resolvidos com o direito de olhos fechados - veja-se, por exemplo, o problema do terrorismo, do crime organizado, da violência urbana generalizada (guerra civil urbana se fala já), ou a questão dos sem-terra - mas com uma abordagem inter-pluri-multi-disciplinar, que compreenda um direito de olhos bem abertos às realidades e aos problemas sociais [...]. Contra muitas doenças culturais - não apenas brasileiras, aliás - que diagnostica Énio Resende, o remédio é, sem dúvida, a Cidadania. E a nova cidadania está aí, despontando: não engravatada e neo-liberal, desprezando, como se foram espúrias, as condições concretas da liberdade, mas convocando até novas formas de intervenção, e dinamizando a própria cultura.
\end{abstract}

Logo, conclui-se que decorre do princípio da dignidade da pessoa humana (art. $1^{\circ}$, III, CF/88) a obrigação do Estado em garantir ao indivíduo um patamar mínimo de recursos, 
capaz de manter-lhe a sobrevivência e de sua família, salvaguardando, em concomitância, dentre outros direitos, o direito à convivência familiar e comunitária da criança e do adolescente.

Ademais, com vistas a evidenciar o caráter de um dos fundamentos da República Federativa do Brasil, qual seja o princípio da dignidade da pessoa humana, que está umbilicalmente ligado ao direito à convivência familiar e comunitária do menor, mostra-se importante frisar a atuação da norma fundamental como diretriz hermenêutica.

Que, para Ingo Sarlet (2002, p. 32):

[...] assume particular relevância a constatação de que a dignidade da pessoa humana é simultaneamente limite e tarefa dos poderes estatais e, no nosso sentir, da comunidade em geral, de todos e de cada um, condição dúplice esta que também aponta para uma paralela e conexa dimensão defensiva e prestacional da dignidade. Como limite, a dignidade implica não apenas que a pessoa não pode ser reduzida à condição de mero objeto da ação própria e de terceiros, mas também o fato de que a dignidade gera direitos fundamentais (negativos) contra atos que violem ou a exponham a graves ameaças. Como tarefa, da previsão constitucional (explícita ou implícita) da dignidade da pessoa humana, dela decorrem deveres concretos de tutela por parte dos órgãos estatais, no sentido de proteger a dignidade de todos, assegurando-lhe também por meio de medidas positivas (prestações) o devido respeito e promoção.

Em mesmo diapasão Wilson Steinmetz (2004, p. 116) leciona que a dignidade da pessoa:

\begin{abstract}
Além da dimensão individual, tem uma dimensão social, intersubjetiva. Há casos em que a lesão da dignidade de uma ou mais pessoas se projeta também sobre a dignidade ou sobre o sentimento de dignidade das demais pessoas integrantes da comunidade humana. Nessa perspectiva, a dignidade da pessoa é um "bem individual" e um "bem social" da comunidade, da humanidade. Por isso, a proteção e promoção desse bem deve ser obrigação de todos e de (no) interesse de todos.
\end{abstract}

Salienta-se, contudo que, por incontáveis vezes, os controles assecuratórios de execução dos direitos fundamentais mostram-se ineficazes, retirando a oportunidade dos infantes de se desenvolverem com sua família e galgarem o máximo grau de dignidade aventado pela Constituição Federal.

Com efeito, seria ingênuo afirmar que o direito à convivência familiar e comunitária, por si só, conduzirá a criança e o adolescente, com total segurança, a caminhos dignos quando atingirem a idade adulta; no entanto, também seria ingênuo afirmar que a ausência do direito à convivência familiar e comunitária não feriria por completo o princípio da isonomia, e não poria por terra quaisquer oportunidades que aos menores possam ser ofertadas. 
Em outras palavras, a exclusão do direito à convivência familiar e comunitária subtrai o direito de escolha da criança e do adolescente, impondo a eles as injustas veredas do abandono, da criminalidade, da falta de afeto, amor e carinho, da opressão, do preconceito, em suma, do mais completo desrespeito a dignidade da pessoa humana.

O que se nota, lamentavelmente, é uma completa desumanização da pessoa, perdendo-se o completo respeito pela essência do ser humano. Podendo afirmar que as mencionadas circunstâncias decorrem da própria ausência de convivência familiar e comunitária. (BAHIA, 2007).

Ademais, além da ineficácia da concretização plena do direito à convivência familiar e comunitária, são de igual modo, ineficazes, em muitas das vezes, os direitos sociais dispostos no artigo $6^{\circ}$ da Carta de 1988, os quais possuem liame complementar e direto para com o direito em tela da criança e do adolescente.

E é nesse diapasão que põe-se a sugestão de possível responsabilização do Estado, a partir da teoria da perda de uma chance, com o precípuo objetivo de responsabilizá-lo por sua inércia, ou ainda, inépcia, quando da efetivação dos direitos da criança e do adolescente.

Mas o que se entende, sob um panorama geral, pela teoria da perda de uma chance?

Nascida na França, a teoria da perda de uma chance - perte d'une chance, ou ainda loss of a chance -, foi criada inicialmente com vistas às atividades médicas e desenvolveu-se a partir da dificuldade em se comprovar os elementos caracterizadores da responsabilidade do profissional da área da saúde, alargando sua aplicação, posteriormente, a outras noções da responsabilidade civil, que não da área médica.

As primeiras delineações sobre a perda de uma chance no Brasil foram inauguradas por Agostinho Alvim, em meados de 1950, que, baseado na teoria francesa, propôs a sua aplicação quando da perda de prazo pelo advogado para a interposição do recurso competente contra decisão desfavorável ao seu cliente, ainda que a matéria em tela apresentasse mínimas chances de ser revertida pelo Tribunal, afirmando que (1965, p. 190-193): “A possibilidade e talvez a probabilidade de ganhar a causa em segunda instância constitua uma chance, uma oportunidade, em elemento ativo a repercutir, favoravelmente, no seu patrimônio [...]”.

De há muito, a teoria vem sendo discutida e estudada pela doutrina pátria, embora sua aplicação pelos operadores do Direito mostrou-se, de certa forma, tímida. Pontuando-se, contudo, que é crescente o número de julgados atinentes a teoria no atual cenário da jurisprudência brasileira, principalmente em se levando em conta a constitucionalização das relações no âmbito privado, o que redefiniu muitos dos conceitos da responsabilidade civil 


\section{A APLICAÇÃO DA RESPONSABILIDADE PELA PERDA DE UMA CHANCE COMO DECORRÊNCIA DO DIREITO FUNDAMENTAL À CONVIVÊNCIA FAMILIAR DE CRIANÇAS E ADOLESCENTES}

com o objetivo de abrigar as garantias constitucionais como, por exemplo, a dignidade humana.

Importando ressaltar, ademais, que sua aplicação fora alargada, e não só diz respeito aos danos advindos da seara médica, mas também daqueles advindos de inadimplementos e falhas contratuais, jogos de azar, concursos públicos, matérias contenciosas, relações familiares, entre outros.

Sublinhando-se, nesse ínterim, que a perda de uma chance está ligada à ideia de dano, constituindo-se como uma modalidade de dano específica e autônoma, o qual é caracterizado pela retirada de uma oportunidade futura de se atingir determinado benefício ou se evitar determinado prejuízo. (FARIAS; ROSENVALD, 2014).

Ainda nesse diapasão afirma Rafael Peteffi da Silva (2007, p. 137) que "a responsabilidade pela perda de uma chance somente é utilizada porque a vítima está impossibilitada de provar o nexo causal entre a conduta do agente e a perda definitiva da vantagem esperada".

Ademais, a constatação de que a responsabilização por danos não poderia mais ficar adstrita apenas à comprovação do elemento 'culpa', culminou no surgimento da chamada responsabilidade objetiva.

Com efeito, a modalidade objetiva tange à responsabilidade cujo reconhecimento não depende de análise da culpa do agente - e, por óbvio, da análise do dolo -, na medida em que há dispensa legal da necessidade de se apreciar a conduta daquele apontado como o agente violador do direito. Exigindo-se, pois, apenas a existência de um comportamento para considerar o autor deste como responsável civilmente pelo direito violado.

Não podendo perder de vista, também, a mudança conceitual sofrida pelo instituto da responsabilidade, na exata medida em que o ato ilícito deixou de ser "a menina dos olhos", deslocando-se, assim, a preocupação à proteção da vítima do dano injusto. (BAHIA, 2007).

De forma a corroborar todo o explanado, enfatiza Sérgio Savi (2006, p. 01) que “[...] inúmeras são as situações na vida cotidiana em que, tendo em vista o ato ofensivo de uma pessoa, alguém se vê privado da oportunidade de obter uma determinada vantagem ou de evitar um prejuízo", situação que, com as devidas adaptações, se amolda perfeitamente a hipótese de não-concreção do direito fundamental à convivência familiar e comunitária pertencente às crianças e aos adolescentes.

Pautando-se pelo liame acima estabelecido, é pertinente demonstrar a materialização do regime jurídico de responsabilização estatal no Brasil. 
Aduz o artigo $37, \S 6^{\circ}$, da Constituição Federal:

\begin{abstract}
Art. 37. A administração pública direta e indireta de qualquer dos Poderes da União, dos Estados, do Distrito Federal e dos Municípios obedecerá aos princípios da legalidade, impessoalidade, moralidade, publicidade e eficiência e, também, ao seguinte:

$[\ldots]$

$\S 6^{\circ}$. As pessoas jurídicas de direito público e as de direito privado prestadoras de serviços públicos responderão pelos danos que seus agentes, nessa qualidade, causarem a terceiros, assegurado o direito de regresso contra o responsável nos casos de dolo ou culpa [...].
\end{abstract}

E, como decorrência do princípio da proteção integral, e em plena consonância ao preceito constitucional, dispõe o artigo 70 do Estatuto da Criança e do Adolescente (Lei 8.069/1990) que "é dever de todos prevenir a ocorrência de ameaça ou violação dos direitos da criança e do adolescente".

Isto quer dizer que dentro do que lhes cabe, é dever da família e da sociedade prevenir a ocorrência ou violação dos direitos das crianças e dos adolescentes. Mas igualmente, também é dever do Estado, de seus entes federados, das pessoas jurídicas de direito público e das pessoas jurídicas de direito privado prestadoras de serviços públicos solidários - zelar pela prevenção de ameaças ou violações dos direitos da criança e do adolescente. Principalmente o direito à convivência familiar e comunitária. E isto se dá, prima facie, a partir da correta e efetiva implementação de políticas públicas, isto é, de prestações positivas. Ou, em outras palavras, direitos de segunda geração.

Com efeito, por tratar-se de prestações de cunho positivo, não pode o Estado ou qualquer um de seus entes, eximir-se do dever que a norma constitucional lhes outorga, alegando, por exemplo, conveniência e/ou oportunidade.

Se tem claro, pois, que nos casos em que a apuração envolver atos ou condutas lesivas e/ou ilícitas praticadas pelas pessoas jurídicas de direito público, bem como pelas pessoas jurídicas de direito privado prestadoras de serviços públicos, a responsabilidade será de cunho objetivo, o que significa dizer que independe do elemento 'culpa', necessitando, para sua concretização, que apenas se demonstre o nexo causal entre o evento danoso e o prejuízo alegado por quem o sofreu.

Frisando-se, nesse diapasão, que o próprio Estado reconheceu sua responsabilidade solidária ao direito fundamental à convivência familiar e comunitária da criança e do adolescente, quando lançou o "Plano Nacional de Promoção, Proteção e Defesa do Direito de Crianças e Adolescentes à Convivência Familiar e Comunitária", aprovado pelos conselhos 


\section{A APLICAÇÃO DA RESPONSABILIDADE PELA PERDA DE UMA CHANCE COMO DECORRÊNCIA DO DIREITO FUNDAMENTAL À CONVIVÊNCIA FAMILIAR DE CRIANÇAS E ADOLESCENTES}

nacionais de Direitos da Criança e do Adolescente (CONANDA) e de Assistência Social (CNAS), restando certo que tanto a União, quanto os Estados-membros, o Distrito Federal e os Municípios terão de definir ações a fim de garantir o direito constitucional das crianças e dos adolescentes à convivência familiar e comunitária com seus familiares e comunidade, possuindo, todos, desse modo, responsabilidades solidárias para colocar em prática as ações definidas no plano em tela.

A partir da perspectiva proposta pelo Plano Nacional, a criança e o adolescente devem ser encarados como indissociáveis do contexto sócio-familiar e comunitário, surgindo daí a necessidade de que o Estado, por qualquer de seus entes, preste o condigno apoio à família de origem, para que, assim, esta possa desempenhar corretamente seu papel precípuo na proteção e cuidado dos filhos.

À vista do elucidado, isto é, após a verificação do modus operandi de responsabilização do Estado pela violação de um dever (obrigação) que lhe era inerente, como o direito à convivência familiar e comunitária das crianças e adolescentes, chega-se a cristalina conclusão de que aludida verificação se coaduna perfeitamente a aplicação da teoria da perda de uma chance.

Assim, ante todo o explanado, tem-se que a teoria da responsabilidade pela perda de uma chance amolda-se perfeitamente à questão posta.

$\mathrm{Na}$ medida em que, em que pese não possa se ter a certeza de que a criança e o adolescente privados do direito jus fundante se tornariam aptos a conviver de forma digna e harmoniosa dentro da sociedade, não é menos verdade que, em não possuindo o direito à convivência familiar e comunitária, fora subtraída pelo Estado, de forma ilícita, tal chance. Não podendo, portanto, ficar a perda da chance à convivência familiar e comunitária da criança e do adolescente sem a devida reparação.

\section{CONSIDERAÇÕES FINAIS}

O estudo buscou demonstrar a relevância do direito fundamental à convivência familiar e comunitária da criança e do adolescente sob o enfoque do princípio fundante do ordenamento jurídico, que é a dignidade humana, bem como dos princípios constitucionais da prioridade absoluta e da proteção integral.

É importante que o melhor desenvolvimento da criança e do adolescente seja oferecido dentro do âmbito familiar e comunitário. Afinal, esse é o momento pelo qual tanto a 
criança, quanto o adolescente, passam a desenvolver suas percepções sobre a realidade que os cerca, desenvolvem o senso crítico, suas opiniões, sua personalidade.

Porém, como explanado, nem sempre é assegurado à criança e ao adolescente a plena convivência no seio familiar e comunitário.

O motivo? A família não tem condições mínimas para oferecer a subsistência digna aos seus componentes. Não porque ela não quer, mas porque o Estado e seus entes federados, não implementam como deveriam as políticas públicas condizentes ao pleno e digno desenvolvimento familiar daquele núcleo.

Desse modo, o presente estudo delimitou-se em apresentar o especial status conferido pela Constituição Federal de 1988 à família, como "base da sociedade", mostrandose como decorrência do status fundamental, o dever de proteção pelo Estado. Nesse diapasão, mesmo com a expressa disposição da Lei Maior, e de expressa regulamentação pelo Estatuto da Criança e do Adolescente, carece a família de efetivo zelo estatal.

A partir desse viés, demonstrou-se ser medida de extrema exceção a retirada da criança e/ou do adolescente quando da impossibilidade de mantença do poder familiar, e, que tal impossibilidade se dá, na grande maioria das vezes, justamente pela inépcia, ou ainda, pela inércia do Estado e de seus entes federados, na satisfação de seu dever de prestação positiva.

Mostrando, por conseguinte, que é de todos a responsabilidade em zelar pelos direitos da criança e do adolescente, mormente, o direito à convivência familiar e comunitária. Entendendo-se por "todos", tanto a família e a comunidade/sociedade, quanto e principalmente, a União, os Estados membros, o Distrito Federal, os Municípios, as pessoas jurídicas de direito público e as pessoas jurídicas de direito privado prestadoras de serviços públicos. Sendo, portanto, solidários entre si e possuidores de responsabilidade objetiva.

Ademais, e de forma a corroborar, fora demonstrado que quando o Estado não implementa efetivamente as políticas necessárias à digna sobrevivência e desenvolvimento do seio familiar, deixando de zelar pelos direitos fundamentais inerentes à família, incluídos por óbvio os da criança e do adolescente, acaba por violar flagrantemente o direito à convivência familiar e comunitária que à criança e ao adolescente deveria ser resguardado como corolário intrínseco da dignidade humana.

Concluindo-se, portanto, que a violação ao direito à convivência familiar e comunitária configura a perda da chance que a criança e o adolescente possuíam de desenvolver-se dignamente ao lado de sua família e de sua comunidade, frutos da mais importante construção do afeto e da afinidade. 
Pontuando-se, como última análise, que, sendo a perda de uma chance uma modalidade de dano autônoma, e, ressaltando-se que a inércia ou inépcia do Estado e de seus entes federados, quando da violação ao direito à convivência familiar e comunitária, configuram a privação da oportunidade da criança e/ou do adolescente de crescer e se desenvolver com sua família e comunidade, nada mais justo do que afirmar a perfeita possibilidade de se aplicar a teoria da perda de uma chance como corolário da convivência familiar e comunitária.

\section{REFERÊNCIAS BIBLIOGRÁFICAS}

ALEXY, Robert. TEORIA DOS DIREITOS FUNDAMENTAIS, Tradução: Virgílio Afonso da Silva da 5a edição alemã de 2006, São Paulo: Malheiros Editores, 2008.

ALVIM, Agostinho. Da inexecução das obrigações e suas consequências. 3. ed. atual. São Paulo: Jurídica e Universitária, 1965.

BAHIA, C. J. A. A responsabilidade do Estado na tarefa de garantir o direito de convivência familiar de crianças e adolescentes. Tese (Doutorado em Direito do Estado) Pontifícia Universidade Católica de São Paulo. São Paulo, 2007.

BARROSO, Luís Roberto. A dignidade da pessoa humana no direito constitucional contemporâneo: a construção de um conceito jurídico à luz da jurisprudência mundial. Belo Horizonte: Fórum, 2012.

BARACHO, José Alfredo de Oliveira. Teoria geral da cidadania: a plenitude da cidadania e as garantias processuais constitucionais. São Paulo: Saraiva, 1995.

BRASIL. Código Civil Brasileiro de 2002. In: Vade Mecum. 8. ed. São Paulo: Revista dos Tribunais, 2016.

BRASIL. Constituição Federal de 1988. In: Vade Mecum. 8. ed. São Paulo: Revista dos Tribunais, 2016.

BRASIL. Estatuto da Criança e do Adolescente - Lei 8.069/90. In: Vade Mecum. 8. ed. São Paulo: Revista dos Tribunais, 2016. 
CUNHA, Paulo Ferreira da. A Constituição viva: cidadania e direitos humanos. Porto Alegre: Livraria do Advogado, 2007.

FARIAS, Cristiano Chaves de; ROSENVALD, Nelson. Curso de direito civil, volume 6: famílias. 6. ed. Salvador: JusPODIVM, 2014.

GAGLIANO, Pablo Stolze; FILHO, Rodolfo Pamplona. Novo curso de direito civil, volume 6: direito de família - as famílias em perspectiva constitucional. 5. ed. São Paulo: Saraiva, 2015.

LOPES, Emília. Os filhos do Estado: a institucionalização de crianças e adolescentes à luz do direito fundamental à convivência familiar e comunitária. Rio de Janeiro: Lumen Juris, 2016.

NETO, José Leite da Silva. Horizontalidade e verticalidade da cidadania. Bauru: Spessotto, 2016.

ONU. Alto Comissariado de Direitos Humanos das Nações Unidas, Status of Ratifications of the Principal International Human Rights Treatis. Disponível em: <http://indicators.ohchr.org/>. Acesso em 10/08/2018.

PEIXOTO, Leonardo Scofano Damasceno. O direito processual constitucional e a efetividade dos direitos humanos. Rio de Janeiro: Lumen Juris, 2017.

PEREIRA, Rodrigo da Cunha. Princípios fundamentais norteadores do direito de família. 2. ed. São Paulo: Saraiva, 2012.

PIOVESAN, Flávia. Temas de direitos humanos. 10 ed., ver., ampl. e atual. São Paulo: Saraiva, 2017.

ROCHA, Nuno Santos. A perda de chance como uma nova espécie de dano. Coimbra: Almedina, 2017.

ROSENVALD, Nelson. O Direito civil em movimento: desafios contemporâneos. Salvador: JusPodivm, 2017.

ROTHENBURG, Walter Claudius. Direitos fundamentais. São Paulo: Método, 2014. 
ROTHENBURG, Walter Claudius. Princípios constitucionais. Segunda tiragem. Porto Alegre: Sérgio Antonio Fabris Editor, 2003.

SARMENTO, Daniel. Dignidade da pessoa humana: conteúdo, trajetórias e metodologia. Belo Horizonte: Fórum, 2016.

SAVI, Sérgio. Responsabilidade civil por perda de uma chance. São Paulo: Atlas, 2006.

SEVERO, Sérgio. Os danos extrapatrimoniais. São Paulo: Saraiva, 1996.

SILVA, Rafael Peteffi. Responsabilidade civil pela perda de uma chance. São Paulo: Atlas, 2007.

SILVA, Virgílio Afonso da. Direitos fundamentais: conteúdo essencial, restrições e eficácia. São Paulo: Malheiros, 2017.

SOROMENHO-MARQUES, Viriato. A era da cidadania. Mem Martins: Biblioteca Universitária, 1996.

STEINMETZ, Wilson. A vinculação dos particulares a direitos fundamentais. São Paulo: Editora Malheiros, 2004. 